\title{
Augmenting one-session treatment of children's specific phobias with attention training to positive stimuli
}

\section{Allison M. Waters ${ }^{\mathrm{a}}$, Lara J. Farrell ${ }^{\mathrm{a}}$, Melanie J. Zimmer-Gembeck ${ }^{\mathrm{a}}$, Ella Milliner $^{\mathrm{a}}$, $^{\text {, }}$} Evelin Tiralongo ${ }^{\mathrm{b} \text { e }}$, Caroline L. Donovan ${ }^{\mathrm{a}}$, Harry McConnell $^{\mathrm{c}}$, Brendan P. Bradley ${ }^{\mathrm{d}}$, Karin Mogg ${ }^{\mathrm{d}}$, Thomas H. Ollendick ${ }^{\mathrm{f}}$

\author{
${ }^{\text {a }}$ School of Applied Psychology, Griffith University, Australia \\ ${ }^{\mathrm{b}}$ School of Pharmacy, Griffith University, Australia \\ ${ }^{\mathrm{c}}$ School of Medicine, Griffith University, Australia \\ ${ }^{\mathrm{d}}$ Psychology, University of Southampton, United Kingdom \\ ${ }^{\text {e }}$ Griffith Health Institute, Griffith University, Australia \\ ${ }^{\mathrm{f}}$ Child Study Centre, Virginia Tech, USA
}

Corresponding author: Dr Allison Waters, School of Applied Psychology, Griffith University, Australia, email: a.waters@griffith.edu.au 


\begin{abstract}
This study examined the efficacy of combining two promising approaches to treating children's specific phobias, namely attention training and one 3-hour session of exposure therapy ('one-session treatment', OST). Attention training towards positive stimuli (ATP) and OST (ATP+OST) was expected to have more positive effects on implicit and explicit cognitive mechanisms and clinical outcome measures than an attention training control (ATC) condition plus OST (ATC+OST). Thirty-seven children (6-17 years) with a specific phobia were randomly assigned to ATP+OST or ATC+OST. In ATP+OST, children completed 160 trials of attention training responding to a probe that always followed the happy face in happy-angry face pairs. In ATC+OST, the probe appeared equally often after angry and happy faces. In the same session, children completed OST targeting their phobic situation/object. Clinical outcomes included clinician, parent and child report measures. Cognitive outcomes were assessed in terms of change in attention bias to happy and angry faces and in danger and coping expectancies. Assessments were completed before and after treatment and three-months later. Compared to ATC+OST, the ATP+OST condition produced (a) significantly greater reductions in children's danger expectancies about their feared situations/object during the OST and at three-month follow-up, and (b) significantly improved attention bias towards positive stimuli at post-treatment, which in turn, predicted a lower level of clinician-rated phobia diagnostic severity three-months after treatment. There were no significant differences between ATP+OST and ATC+OST conditions in clinician, parent, or child-rated clinical outcomes. Training children with phobias to focus on positive stimuli is effective in increasing attention towards positive stimuli and reducing danger expectancy biases. Studies with larger sample sizes and a stronger 'dose' of ATP prior to the OST may reveal promising outcomes on clinical measures for training attention towards positive stimuli.
\end{abstract}




\section{Introduction}

Specific phobias are a significant problem affecting between 5-10\% of children and adolescents across community and clinical samples (see Kessler et al., 2005; Ollendick, Hagopian, \& King, 1997). These disorders typically precede other phobias and anxiety, mood and substance use disorders in adulthood (Gregory et al., 2007; Kendall, Safford, FlannerySchroeder, \& Webb, 2004), and are associated with academic difficulties (Ialongo, Edelsohn, Werthamer-Larsson, Crockett, \& Kellam, 1995), and social and personal distress (Ollendick \& March, 2004). Although the prevention and treatment of childhood phobias has been identified as a major health imperative (Gregory et al., 2007; Ollendick et al., 2009), fewer than $10 \%$ of adults report ever seeking treatment for their phobias despite suffering with the disorder for more than 20 years on average (Stinson et al., 2007).

Cognitive-behavioural therapy (CBT) is a well-established psychological treatment for childhood anxiety disorders that involves experimentation with alternative, more adaptive behaviours and cognitions, primarily through in vivo or imagined exposure to feared stimuli or situations and restructuring of cognitive beliefs and appraisal processes (Farrell, Waters, Milliner, \& Ollendick, 2012; Waters, Wharton, Craske, \& Zimmer-Gembeck, 2008). Extinction learning is the theoretical basis of exposure therapy (see Boschen, Neumann, \& Waters, 2009 and Vervliet, Craske, \& Hermans, 2012 for reviews), whereby repeated exposure to the feared stimulus or situation (i.e., conditional stimulus, CS) provides corrective evidence that violates expectancies regarding danger (unconditional stimulus, UCS) and coping estimates (Craske et al., 2008). Learning that the CS is not associated with the UCS during exposure therapy gradually reduces distress (i.e., the unconditional response; UR). Thus, exposure therapy does not remove the original fear learning but leads to additional, new learning that the stimulus or situation is safe (Bouton, 2002). Long-term fear extinction/successful treatment outcomes therefore depend on whether the original fear 
learning or new extinction learning is retrieved when encountering the feared stimulus or situation again in the future (Boschen et al., 2009).

With between 40-50\% of children not diagnosis-free following exposure-based CBT (see Rapee, Hudson, \& Schniering, 2009, for a review), a considerable number of anxious children either do not respond at all or fail to achieve sustained improvement. Moreover, many who do respond still exhibit residual symptoms, which predict high rates of relapse at long term follow-up (Ginsburg et al., 2014). Further still, many children with specific phobias do not have access to efficacious treatments in their communities (Kendall, Settipani, \& Cummings, 2012), whereas the cost of these interventions may prohibit access for many others (Essau, 2005).

To enhance interventions and their application, and to reduce costs and make therapy more easily accessible, an intensive form of exposure-based CBT, called "one session treatment” (OST; Davis \& Ollendick, 2005; Ollendick, King, \& Chorpita, 2006; Öst, 1997) has been developed that is typically delivered individually in one session (lasting up to 3 hours) using a standard format involving three principles of (a) participant modelling, (b) in vivo exposure, and (c) reinforced practice. This treatment has been designated as an evidence-based treatment for adults with specific phobias (Chambless \& Ollendick, 2001; Zlomke \& Davis, 2008) and shown to be superior to waitlist and active control conditions in several small- and large-scale clinical trials of children with specific phobias (e.g., Muris, Merckelbach, Holdrinet, \& Sijsenaar, 1998; Öst, Svensson, Hellstrom, \& Lindwall, 2001; Ollendick et al., 2009). After the OST, between 50-80\% of children with diverse types of specific phobias were diagnosis free by post-treatment and/or 6-month follow-up (Öst et al., 2001; Ollendick et al., 2009). Although such results are encouraging in that they demonstrate that OST can produce similar treatment outcomes as standard CBT packages, they nevertheless indicate that a significant proportion of children with specific phobias still do not benefit or achieve sustained improvement after the OST. This highlights the continued 
need for more research on ways to enhance outcomes from intensive formats of exposurebased CBT.

Recent advances in understanding the cognitive and neurobiological correlates of anxiety disorders in children can provide insight into new directions for novel interventions (see Waters, Farrell, \& Schilpzand, 2013, for a review). Attention bias modification training (ABMT) is an emerging treatment producing a moderate effect size based on studies with adults (see Hakamata et al., 2010 for a review). ABMT aims to modify implicit attention biases towards threat stimuli which are thought to maintain anxiety (see Bar-Haim et al., 2007 for a review) by teaching participants to rapidly direct their attention away from threatening and toward neutral cues, thereby reducing anxiety symptoms (cf. Hakamata et al., 2010; Hallion \& Ruscio, 2011). Most of the studies on ABMT use a modified visual probe paradigm (MacLeod, Mathews, \& Tata, 1986), a computer-based task, originally developed for attention bias assessment. This task presents a series of stimulus pairs (e.g., a threat face and neutral face presented side by side) and, after each stimulus pair disappears, a probe (e.g. small dot or arrow) replaces either the threat or neutral stimulus. Visual probe ABMT modifies attention biases by repeatedly presenting probes after neutral and not following threat stimuli, thereby training participants to preferentially direct their attention to neutral information (e.g., Schmidt, Richey, Buckner, \& Timpano, 2009).

Empirically, a redirection of attention can be achieved in subclinical and clinical participants, and this attention modification often results in a decrease of both observed and self-reported anxiety symptoms (e.g., Amir, Beard, Burns, \& Bomyea, 2009; Amir, Weber, Beard, Bomyea, \& Taylor, 2008; Amir et al., 2009; Amir \& Taylor, 2012; Hazen, Vasey, \& Schmidt, 2009; See, MacLeod, \& Bridle, 2009; see Clarke, Notebaert \& MacLeod, 2014, for a review). However, a number of studies have failed to show favourable effects of ABMT on threat attention bias and/or anxiety levels in subclinical and clinical samples of adults (e.g., Behar, McHugh, Peckham, \& Otto, 2010; Eldar \& Bar-Haim, 2010; Julian, Beard, Schmidt, 
Powers, \& Smits, 2012; McNally, Enock, Tsai, \& Tousain, 2013; Neubaeur et al., 2013; Rapee et al., 2013; Van Bockstaele, Verschuere, De Houwer, \& Crombez, 2010).

Research on threat attention bias and ABMT in anxious children has lagged behind that with adults; even so, early findings have been similarly mixed (Bar-Haim, Morag, \& Clickman, 2011; Bechor et al., 2013; Eldar et al., 2012; Rozenman, Weersing, \& Amir, 2011; Cowart \& Ollendick, 2011). Specifically, findings regarding the direction of threat attention bias have been more varied in anxious children than anxious adults with threat vigilance and threat avoidance often observed in anxious children compared to healthy controls (see Salum et al., 2013; Waters, Bradley, \& Mogg, 2014). Thus, as biased attention towards threat only manifests in a subset of anxious children (e.g., Bechor et al., 2013; Cowart \& Ollendick, 2011), some studies have addressed this issue by excluding children who do not show a pretreatment bias towards threat stimuli (e.g., Eldar et al., 2012). While this might mitigate potential adverse effects, it limits clinical applicability of ABMT to only a subset of anxious children. Other recent studies combining ABMT with a full course of CBT (e.g., Shechner et al., 2014) found that both active and placebo ABMT augmented CBT outcomes based on clinician and parent-reports of anxiety compared to CBT alone. However, a shift of attention away from threat after treatment was common to all three treatments leaving it unclear whether change in attention to threat due to ABMT contributed to the differential outcomes. Nevertheless, these findings encourage further research on combined treatments.

Training anxious children to preferentially focus attention on positive stimuli could potentially overcome some of the problems in applying ABMT to children. Using a visualsearch training paradigm with adults, Dandeneau and colleagues (2007) found that participants in the positive training condition (i.e. trained to attend preferentially to smiling rather than disapproving faces) experienced significant reductions in physiological and selfreport stress responses, relative to participants in the control condition. Other findings suggest that training attention towards positive stimuli and rewards might minimize anxiety or stress 
reactivity in adults (e.g., Johnson, 2009; Wadlinger \& Isaacowitz, 2008; Heeren, Reese, McNally, \& Philippot, 2012; Taylor, Bomyea, \& Amir, 2011; but see McNally et al., 2013 for null results) and anxious children and adolescents (Waters, Pittaway, Mogg, Bradley, \& Pine, 2013; De Voogd, Wiers, Prins, \& Salemink, 2014). Despite some exceptions (e.g., McNally et al., 2013) which may be due to differences in methodology and sample characteristics, these studies suggest that attending preferentially to positive stimuli helps reduce emotional reactivity and distress when confronted with stressful and challenging tasks (e.g., speech task; anagrams) (e.g., Heeren et al., 2012; Johnson, 2009; Taylor et al., 2011). Since exposure therapy similarly involves dealing with challenging circumstances, such as feared objects and situations, ABMT towards positive stimuli immediately preceding exposure-based treatments, such as OST, might enhance treatment outcomes.

Several factors may account for a beneficial effect of training attention to positive stimuli on exposure therapy. For example, it may heighten activation of positive thoughts and emotions, which may in turn contribute to more positive appraisals of the situation/objects that participants subsequently deal with during exposure. Also, increased attention to positive stimuli may generalise to the exposure session, thereby enhancing attention to positive cues (e.g. information related to safety, success and mastery) and the processing of corrective information that in turn speeds-up the violation of danger expectancies associated with the feared object/situation. This seems pertinent to exposure therapy where increasing strategies to encourage processing of disconfirming stimuli may be particularly beneficial (Craske et al., 2008). Increasing attention to positive stimuli may also assist emotion regulation by reducing attention to negative aspects of stressful situations (Taylor et al., 2011). Additionally, attention training to positive stimuli may relate to putative underlying motivation systems; specifically, it may enhance approach motivation (Pessoa, 2009; Crocker et al., 2013), which prioritises allocation of cognitive resources towards reward- 
related information, and supports approach behaviours towards reward cues, which in turn may counteract avoidance tendencies that are likely to interfere with exposure therapy.

Therefore, the main aim of this study was to determine whether ABMT towards positive stimuli plus OST (ATP+OST) leads to greater reductions in anxiety diagnosis severity ratings, mean number of diagnoses and symptom severity scores at post-treatment and three-month follow-up in comparison with an ABMT control condition plus OST (ATC+OST). We also examined whether ATP+OST increased attention to positive stimuli compared to the ATC+OST condition (e.g., De Voogd et al., 2014; Waters et al., 2013). No specific hypotheses were formulated regarding change in attention bias to threat stimuli given the inconsistent evidence of such a threat bias in anxious children prior to treatment (e.g., Eldar et al., 2012). Moreover, to test whether training attention towards positive stimuli assists with the accumulation of corrective information that violates danger and coping expectancies during OST (Craske et al., 2008), we examined whether feared outcome and coping expectancies declined more during the OST and were maintained to three-month follow-up in the ATP+OST compared to the ATC+OST condition. Finally, based on recent evidence that the magnitude of post-treatment attention bias predicts subsequent emotional responses to stressful tasks (e.g., Clarke, MacLeod, \& Shirazee, 2008; Johnson, 2009; Taylor et al., 2011) and longer-term (i.e., one-month) therapeutic improvement (i.e., Reinecke, Waldenmaier, Cooper, \& Harmer, 2013), we examined whether post-treatment attention bias towards positive stimuli predicts phobia diagnostic severity at three-months follow-up in the $\mathrm{ATP}+\mathrm{OST}$ relative to the ATC+OST condition.

\section{Method}

\section{Participants}

Parents of 68 children initially contacted the research team in response to study advertisements circulated through local schools, paediatricians, GPs, other mental health and community health agencies, and local newspapers. Children in the final sample satisfied the 
following criteria: (i) meeting criteria for a diagnosis of specific phobia, (ii) no diagnoses of organic brain injury, psychosis, pervasive developmental disorder or learning disability, vision impairment or physical disability that would prevent using a computer; (iii) no psychological or pharmacological treatment at the time of enrolment in or during the study, and (iv) between 6 and 17 years of age. Comorbid externalising behavioural disorders, attention deficit hyperactivity disorder, major depressive disorder and dysthymia were not exclusionary criteria providing they were not the principal diagnosis (i.e., most severe).

After exclusion (see Figure 1 for the flow of participants through the study), thirtyseven children with a specific phobia were recruited into a randomised, double-blind controlled trial approved by the Griffith University Human Research Ethics Committee. Participants were randomly assigned to receive ATP+OST or ATC+OST. Of the 37 intent-totreat $(\mathrm{ITT})$ children recruited $(\mathrm{ATP}+\mathrm{OST}=19 ; \mathrm{ATC}+\mathrm{OST}=18)$, one child randomised to ATP+OST did not commence treatment after assignment; two did not complete the posttreatment assessment (ATP $=1 ;$ ATC $=1)$, and two did not complete the three-month followup assessment $(\mathrm{ATP}=1$; $\mathrm{ATC}=1$ ) resulting in a completion sample of 32 children at followup $(\mathrm{ATP}+\mathrm{OST}=16 ; \mathrm{ATC}+\mathrm{OST}=16)$.

Of the ITT sample, specific phobia was the principal diagnosis (i.e., most severe) in 34 cases, of equal severity to another anxiety diagnosis in two cases (other diagnosis: GAD; separation anxiety disorder), and secondary to social phobia in one case. The types of specific phobia were as follows: animal $(n=14)$ (e.g., dogs, cats, bees), natural environment $(n=12)$ (e.g., dark; thunderstorms), situational ( $n=2)$ (e.g., heights), and other $(n=9)$ (e.g., vomiting, costumed character). Children had an average of 4.1 diagnoses. Thirty-one completing children had at least one comorbid anxiety disorder; one also had comorbid major depressive disorder; another had comorbid dysthymia; another had comorbid oppositional defiant disorder; and two had comorbid attention deficit hyperactivity disorder, both of whom 
were stabilised on medication (Concerta; Ritalin) by paediatricians prior to the trial. Two children were medicated for asthma (Symbicort; Flixotide).

Insert Figure 1

\section{Design}

Children were randomized using a computer-generated list to either ATP+OST $(n=$ 19) or ATC+OST $(n=18)$, with blinding managed by the project coordinator. All investigators were blind to children's assigned attention training condition, as were assessors, therapists, and participating children and their parents.

\section{Measures}

Diagnostic status. The Anxiety Disorders Interview Schedule for DSM-IV, Parent and Child Interviews (ADIS-IV-C/P; Silverman \& Albano, 1996) were used to assess children's diagnostic status. Children received diagnoses for any disorder assessed with the ADIS-IV-C/P for which they received a clinician severity rating (CSR) of four or higher (scale 0-8), one of which had to be a specific phobia to be included in the study even if another anxiety disorder was more severe than the specific phobia and providing that any non-anxiety disorder was less severe than the specific phobia. The ADIS-IV-C/P was administered over the telephone with parents (all mothers) and face-to-face with children. The telephone version of the ADIS-IV-C/P has been found to be as reliable as face-to-face administration (Lyneham \& Rapee, 2005). The ADIS-IV-C/P has demonstrated excellent reliability and strong concurrent validity with other measures of childhood anxiety, (Silverman, Saavedra \& Pina, 2001; Wood, Piacentini, Bergman, McCracken, \& Barrios, 2002). The ADIS-IV-C/P interviews were administered by 10 graduate clinical students trained by clinical psychologists experienced in anxiety assessment and ADIS-IV-C/P administration and reviewed in supervision. The outcomes of the parent and child interviews were discussed with the project team during weekly supervision sessions to arrive at consensus diagnoses and CSRs. Independent assessors were used at each assessment time- 
point and were blind to children's assigned condition and diagnostic profiles at previous assessments. Twenty percent of interviews were audio-taped and coded by an independent rater blind to children's diagnostic status and treatment condition. Inter-rater reliability showed excellent agreement for both disorders present and absent (e.g., disorders present: principal diagnosis $\kappa=.91$; second diagnosis $\kappa=0.88$; third diagnosis $\kappa=0.86$ ).

Clinical symptoms. The Spence Children’s Anxiety Scale, Parent and Child versions (SCAS-P \& SCAS-C; Nauta et al., 2004; Spence, 1998) are 39-item (parent report measure) and 45-item (child self-report measure; 6 positive filler items) questionnaires that both contain 4-point response scales ( $0=$ never true to $3=$ always true), yield total scores reflecting symptom severity, and possess sound psychometric properties (e.g., Cronbach alpha $=.93 ;$ 6-month test-retest reliability co-efficient $=.60)($ Spence, 1998). Mean SCAS-P total scores of 14.2 and 31.8, and mean SCAS-C total scores of 18.8 and 32.2 are reported for non-clinical and clinically-anxious children, respectively (Nauta et al., 2004; Spence, 1998). The SCAS-P and SCAS-C were completed at pre- and post-treatment and at three-month follow-up.

The Short Mood and Feelings Questionnaire, Parent and Child versions (SMFQ-P and SMFQ-C; Angold, Costello, \& Messer, 1995) were used to assess children’s depressive symptoms. Both versions of the SMFQ comprise 13 items which ask the respondent to rate the child's feelings and actions ( 0 = not true; 1 = sometimes true; 2 = always true) over the preceding two-week period. A score of 8 or more is considered significant (Angold et al., 1995). The internal reliability coefficients have been found to be good (Cronbach's alpha = 0.87) (Angold et al., 1995). The SMFQ-P and SMFQ-C were completed at pre- and posttreatment and at three-month follow-up.

Global functioning. The Children's Global Assessment Scale (CGAS; Shaffer et al., 1983) was used to assess change in severity of overall disturbance in functioning at each time 
point. The CGAS rates global functioning from 0-100, with higher scores indicating better overall functioning. The CGAS has been shown to be reliable between raters and across time and has demonstrated both discriminant and concurrent validity (Shaffer et al., 1983).

Attention bias. The visual probe task was presented on a Dell Optiplex computer with a 17 inch, $75 \mathrm{~Hz}$ CRT colour monitor in a research laboratory at Griffith University. Briefly, the task stimuli included grey-scaled photographs of 64 pairs of adult faces (half male, half female), each face pair was the same person and each photograph illustrated an emotional expression (happy, angry, and neutral). The task consisted of 80 trials, 32 trials were happy-neutral face pairs and 32 trials were angry-neutral face pairs, and 16 trials comprised of neutral-neutral face pairs. The facial stimuli were the same as those utilised in prior paediatric studies (e.g. Monk et al., 2006; Pine et al., 2005; Waters et al., 2008; see Bradley, Mogg, Falla \& Hamilton, 1998, for details of the stimulus set).

Each trial began with a fixation cross presented in the centre of the screen for $500 \mathrm{~ms}$, followed by a face pair for 500ms. A target probe (asterisk) appeared in the location of one of the preceding pictures. For emotional face trials (i.e. angry-neutral, happy-neutral face pairs), the emotional face and the asterisk were presented equally on the left or right side of the screen, therefore for half of the trials, the probe was presented in the same spatial location as the emotional face (congruent trials), and for the other half of the trials the probe was presented in the opposite spatial location as the emotional face (incongruent trials). Participants were required to immediately, and as accurately as possible, indicate the spatial location of the probe (left or right of the computer screen) using the corresponding computer keys. The intertrial interval varied randomly from 750 to 1250 milliseconds. The task began with 10 random practice trials, followed by one block of 80 trials.

Danger expectancies and coping estimates. Children rated their expectancy about the likelihood of their feared outcome occurring (i.e., danger expectancy) using 0-8 rating scales $(0=$ not at all $-8=$ definitely $)$ and their estimates of their coping ability $(0=$ not at all 
$-8=$ very sure) at pre-treatment assessment, the start and the end of the first, second and third hour of the OST and again at post-treatment and three-month follow-up assessments.

Emotional reactivity during treatment. The State Anxiety Subscale of the StateTrait Anxiety Inventory for Children (STAI-C; Spielberger, 1973) is a 20-item measure of state anxiety that uses a 3-point response scale (not at all - very) to assess anxiety in children "at that very moment” and was completed before and after attention training and after the OST to examine whether anxiety levels were equivalent in each attention training condition. The STAI-C has good psychometric properties (Spielberger, 1973).

Consistent with Taylor et al. (2011), we also assessed changes in positive affect before and after attention training and after the OST to examine potential affective priming effects of attention training to positive stimuli. Positive affect was measured with the five items used by Taylor et al. (2011) (i.e., pleased, friendly, satisfied, happy, enthusiastic). Items were rated on a 5-point response scale with anchors of very slightly/not at all to extremely, and were summed to create a total positive affect score, whereby higher scores reflected greater subjective positive affect.

Treatment: attention training. Both attention training conditions were presented on a Dell Optiplex computer with a 17 inch, $75 \mathrm{~Hz}$ CRT colour monitor in a therapy room in the Psychology Clinic. Face stimuli in both conditions were from the Nim Stim face stimulus set (Tottenham et al., 2009) and consisted of grey-scale photographs of 32 pairs of faces (half male, half female), each face pair was the same person and each photograph illustrated either a happy or angry facial expression. Both conditions consisted of 10 practice trials and 160 training trials. In both conditions, children saw happy-angry adult face pairs presented sideby-side for $500 \mathrm{~ms}$ after which time the face pairs were replaced with an asterisk probe behind one of the faces. In the ATP+OST condition, the probe always followed the happy face, in the ATC+OST condition, the probe followed the angry and happy face equally often. Children pressed one of two keys on the keyboard to indicate which side - left or right - the 
probe appeared on the screen. Both training conditions took approximately 15 min to complete and children completed either ATP or ATC immediately before starting the OST. Therapists were never informed about the rationale or differences between the two training conditions and both conditions were given file names that did not identify their purpose. Smiling facial expressions were used as the positive training stimuli given that faces have strong ecological validity (Waters et al., 2008), they have been used repeatedly in prior ABMT studies (Dandeneau et al., 2007; Waters et al., 2013; De Voogd et al., 2014) and the expression of happiness is correctly categorised as a positive class of stimuli from a very young age (Boyatzis, Chazan, \& Ting, 1993; Gosselin \& Larocque, 2000).

Treatment: OST. This treatment followed the principles described by Ollendick et al. (2009) and Öst (1997). Fifteen therapists who were all clinical psychology graduate students in their second or their year of clinical training at Griffith University received an intensive, two-day workshop on OST from the last author (THO) at Griffith University. Seven of these attendees served as therapists in this study. The workshop covered the key clinical features of specific phobias, the core principles of and empirical literature supporting OST, videotapes of sessions of OST, detailed review of case material and the development of treatment plans for various types of phobias. Another workshop was held two months later with the first and second authors (AMW, LJF) to review additional case material and the study assessment and treatment protocols.

The treatment was manualised but delivered flexibly ( Öst \& Ollendick, 2001), maximized to three hours, and adjusted to the developmental level of each child. The guiding principle of treatment was the cognitive-behavioural analysis of the child's feared outcome expectancies about what would happen when encountering the phobic object or situation. The treatment was based on the rationale that the child's overestimation of threat and danger and/or underestimation of coping maintain his or her escape and avoidance behaviour. These 
expectancies then prevent the child from obtaining new information that can correct the biased expectancies.

Treatment consisted of initial psychoeducation followed by graduated exposure in vivo, embedded in a series of behavioural experiments that the child was encouraged to attempt in order to obtain new information about the phobic object or situation. The children rated their feared outcome and coping expectancies after each hour of treatment. Examples of exposure situations for heights included riding elevators and standing on ladders and balconies of tall buildings, whereas exposure situations for a dog phobic child involved interacting with three dogs (one per hour) of different sizes and activity levels. All of the treatments lasted the full three hours. In no case did a child ask to end the treatment before the three hours were up. No adverse events were observed during treatment.

\section{Procedure}

Pre-treatment. Upon referral, an initial telephone screen was conducted with a parent to address the exclusion criteria and assess the presence of a specific phobia. If a child appeared to meet inclusion criteria, the information sheet and consent form was sent to parents and signed copies returned via post or email. Next, the parent interview schedule of the ADIS-IV-C/P was conducted over the telephone, and then both the parent and child attended two appointments at the University during which time the child version of the ADIS-IV-C/P, questionnaires, the visual probe task, and danger and coping expectancies were completed. A brief functional analysis of the child's phobia was also undertaken. The outcomes of the two interviews were discussed with the project team during weekly supervision sessions to arrive at consensus diagnoses and CSRs. Individual treatment plans were prepared after the assessment phase was completed and were reviewed in supervision with the first author and the project team.

Treatment. After initial orientation to the treatment session, parents completed questionnaires in the therapy room while the child completed the assigned attention training 
program in another therapy room. The child completed the STAI-C State Anxiety Subscale and the Positive Affect questions and then the therapist entered a filename they were given in the child's file into the computer which started the assigned training condition. They explained via a script that the child would see a fixation cross and then two faces presented side-by-side on the screen followed by a star $\left(^{*}\right)$ in the centre of one of the face locations to which the children should respond, by pressing one of two keys on the computer keyboard, whether the asterisk was on the left or the right hand side of the screen. Children completed 10 practice trials, followed by 160 attention training trials. Immediately after the training, the therapist saved and closed the program, children completed the STAI-C State Anxiety Scale and the Positive Affect questions, and the child and therapist returned to the therapy room to commence the OST. Parents moved to the waiting room and were given psychoeducation material to read about phobias and exposure-based treatments.

The OST began with psychoeducation about the child’s phobic stimulus or situation and then moved onto the behavioural experiments for the remainder of the 3 hours. Children gave their danger and coping expectancy ratings at the start, and at the end of the first, second and third hour of OST and completed the STAI-C State Anxiety Scale and the Positive Affect questions at the end of the session. Parents and children were debriefed and each family was instructed to identify appropriate exposure activities the child could undertake over the next four weeks. A follow-up call by the therapist was conducted once per week for four weeks to review progress and problem solve any difficulties that had arisen.

Post-treatment. One week after the treatment session, the parent version of the ADISIV-C/P was conducted over the telephone, and children and parents attended an appointment at the University during which time the ADIS-IV-C/P child version, questionnaires, danger and coping expectancy ratings, and the visual probe task were completed. These interviews and assessments were completed by an independent assessor blind to children’s diagnostic profile and assigned condition. 
Three-month follow-up. The parent and child versions of the ADIS-IV-C/P were completed over the telephone, parent questionnaires were sent home and returned via post and child questionnaires and danger and coping expectancy ratings were assessed over the telephone at three-month post-treatment follow-up. These interviews were completed by another independent assessor blind to children's diagnostic profile and assigned condition. The visual probe task was not completed at this assessment.

\section{Response definitions, data screening and statistical analyses}

Attention bias. Attention bias scores derived from the visual probe task were determined using reaction time (RT) to probes in milliseconds. Incorrect responses and RT outliers were first excluded, the latter were defined as RTs less than 200 ms, or more than 3 standard deviations above the participant's response mean (Waters et al., 2008). Ten children did not complete the task at pre- or post-treatment ( $=6$ ATC+OST; $n=4$ ATP+OST) due to administration error. There were no significant differences between groups in errors (4.2\%), outliers (1.1\%) or overall mean RT (515 ms).

Attention bias scores were calculated by subtracting the average RT on congruent trials (probe presented in the same location as the emotional face) from the average RT on incongruent trials (probe presented in the opposite spatial location as the emotional face). Attention bias scores for angry and happy faces were subjected to separate 2 (Group) x 2 (Time) mixed factorial ANOVAs. Partial eta squared $\left(\eta^{2}\right)$ was calculated as an estimate of effect size. Centred post-treatment attention bias scores were also used in regression analyses to predict change in phobia diagnosis CSRs at three-month follow-up.

Statistical overview. Intent-to-treat analyses were computed using the last point carried forward method (e.g., Ollendick et al., 2009; Spence, Holmes, March, \& Lipp, 2006; Waters, Ford, Wharton, \& Cobham, 2009, Waters et al., 2013). For diagnostic and symptom measures, ITT analyses were based on data from 19 children in the ATP+OST condition and 18 children in the ATC+OST condition. Completer analyses of diagnostic measures were 
based on data from 16 children in the ATP+OST condition and 16 children in the ATC+OST condition; completer analyses of the SCAS-P and SMFQ-P were based on data from 12 children in the ATP+OST condition and 13 children in the ATC+OST condition; and completer analyses of the SCAS-C and SMFQ-C were based on data from 13 children in the ATP+OST condition and 12 children in the ATC+OST condition. Completer analyses of attention bias scores were based on data from 14 children in the ATP+OST condition and 12 children in the ATC+OST condition, and ITT analyses were based on data from 17 children in the ATP+OST condition and 14 children in the ATC+OST condition as the five children who discontinued treatment/were lost to follow-up (see Figure 1) had useable pre-treatment visual probe task data.

\section{Results}

\section{Group Comparisons and Control Analyses}

Continued versus discontinued participants. Children who discontinued $(\mathrm{n}=5)$ versus completed the study $(\mathrm{n}=32)$ did not differ on demographic or symptom variables at pretreatment except for parent marital status, $\chi^{2}{ }_{1}=6.99, p=.02$ (Fisher's exact test). Four of the five children who dropped out (80\%) had parents who were either divorced, de facto, or a single parent compared to $20 \%$ of the parents of children who completed the study.

$A T P+O S T$ versus ATC+OST participants. Groups did not differ significantly with respect to child gender, country of birth, parent marital status, who the child resided with, mother or father years of education, or family income, based on either ITT or completer analyses, all $p>.10$, (see Table 1 ). Groups did not differ significantly in terms of pretreatment severity of phobic or principal diagnosis, number of diagnoses, all $t<1.55$, all $p>$ .13 , or type of specific phobia diagnosis, $\chi^{2}{ }_{1}=0.14, p=.71$ (Fisher's exact test). Groups did not differ in severity of anxiety and depressive symptoms or global functioning at pretreatment, all $t<1.65$, all $p>.11$, with the exception of SCAS-P total scores for which the 
ATP group had significantly higher scores than the ATC group (ITT: $t(35)=2.47, p=.02$; completer: $t(30)=2.33, p=.03)(\text { see Table } 1)^{1}$.

Insert Table 1

Groups also did not differ in momentary mood changes during treatment. The 3

(Time: before attention training; after attention training; after OST) $\times 2$ (Group: ATP+OST, ATC+OST) mixed factorial ANOVAs of children's STAI-C state anxiety ratings and positive affect scores revealed significant main effects of Time, based on ITT analyses, $F(2,34)=$ 6.56, $p=.004, \eta^{2}=.31$ and $F(2,34)=12.68, p<.001, \eta^{2}=.43$ respectively, and completer analyses, $F(2,29)=6.19, p=.007, \eta^{2}=.33$ and Time, $F(2,29)=9.85, p=.001, \eta^{2}=.45$ respectively, but no other significant main or interacting effects, $F^{\prime}$ s $<3.0, p>.09$ (see Table 2). For both ITT and completer analyses, the Time main effects were due to lower STAI-C state anxiety ratings and higher positive affect ratings after the OST compared to before and after attention training (all $p<.01$ ), which did not differ significantly $(p>.21)$.

Insert Table 2

\section{Change in attention bias towards positive and threat stimuli}

Happy faces. The Time $\times$ Group mixed factorial ANOVA of happy face bias scores revealed a significant interaction based on both ITT and completer analyses, $F(1,29)=4.29$, $p=.047, \eta^{2}=.13$ and $F(1,24)=4.48, p=.045, \eta^{2}=.16$ respectively. Bias scores changed significantly from pre- to post-treatment in the direction of towards happy faces in the ATP group, based on ITT and completer samples, $t(16)=3.91, p=.006$ and $t(13)=3.88, p=.002$ respectively, whereas change was not significant in the ATC group, both $t<.039, p>.97$. Happy face bias scores were not significantly different between groups at pre- or posttreatment in either analysis (all $t<1.21$, both $p>$.24) (see Figure 2, left panel). 
Angry faces. The Time $\times$ Group mixed factorial ANOVA of angry face bias scores revealed no significant effects, based on ITT and completer analyses, all $F<.34$, all $p>.57$ (see Figure 2, right panel).

\section{Insert Figure 2}

\section{Change in Danger Expectancies and Coping Estimates}

Danger Expectancies. The mixed factorial ANOVA of children's danger expectancies rated during the OST revealed a significant Time $\times$ Group interaction in both ITT and completer analyses, $F(3,33)=2.98, p=.046, \eta^{2}=.22$ and $F(3,28)=3.00, p=.046, \eta^{2}=.22$ respectively (see Figure 3, upper left panel). The main effects of Time were significant in both groups based on ITT and completer samples, ATP: $F(3,16)=14.28, p<.001, \eta^{2}=.74$ and $F(3,13)=12.15, p<.001, \eta^{2}=.71$ respectively; ATC: $F(3,15)=4.27, p=.023, \eta^{2}=.46$ and $F(3,13)=3.96, p=.03, \eta^{2}=.48$ respectively. However, follow-up comparisons after correction for multiple comparisons based on ITT and completer samples revealed that danger expectancies decreased significantly among the ATP+OST group from the start to the end of the first hour (both $p<.001$ ), did not change significantly by the end of the second hour (both $p>.27$ ) then decreased significantly by the end of the third compared to the second hour of exposure therapy (both $p<.013$ ). In contrast, post hoc tests showed no significant changes in expectancies in the ATC+OST group (all $p>.058$ ). Moreover, pairwise comparisons between groups found that the ATP+OST group had significantly lower danger expectancies at the end of the third hour compared to the ATC+OST group, based on both ITT and completer analyses (both $p=.046$ ). Group differences were not significant at the other time-points (all $p>.23$ ) (see Figure 3, upper left panel).

\section{Insert Figure 3}

The mixed factorial ANOVA of danger expectancy ratings following OST (i.e., using three levels of Time: pre-treatment, post-treatment, three-month follow-up) revealed 
significant Time main effects based on ITT and completer analyses, $F(2,34)=26.73, p<$ $.001, \eta^{2}=.62$ and $F(2,29)=30.25, p<.001, \eta^{2}=.69$ respectively and significant Time $\times$ Group interactions, $F(2,34)=4.38, p=.02, \eta^{2}=.21$ and $F(2,29)=6.77, p=.004, \eta^{2}=.33$ respectively (see Figure 3, lower left panel). The main effects of Time were significant in each group, ATP+OST: ITT: $F(2,17)=22.96 p<.001, \eta^{2}=.74$, Completer: $F(2,14)=$ 29.60, $p<.001, \eta^{2}=.83 ;$ ATC+OST: ITT: $F(2,16)=5.34, p=.017, \eta^{2}=.40$, Completer: $\mathrm{F}(2,14)=4.47, p=.03, \eta^{2}=.39$. Follow-up comparisons based on ITT and completer analyses revealed that in the ATP+OST group, danger expectancies were significantly lower at post-treatment and three-month follow-up compared to pre-treatment (all $p<.001$ ). In the ATC+OST group, there was a significant decrease from pre- to post-treatment in both ITT and completer analyses (both $p<.01$ ), but expectancies were not significantly different at three-month follow-up compared to those at pre- (both $p>.08$ ) or post-treatment (both $p=$ .98). The ratings were significantly lower at post-treatment in the ATP+OST group than the ATC+OST group (both $\mathrm{p}<.046$ ), but group differences were not significant at three-month follow-up (both $p>$.11).

Coping expectancies. The same two mixed factorial analyses of children's ratings of coping expectancies during OST and following OST (i.e., to three-month follow-up) based on ITT and completer analyses revealed significant main effects of Time, ITT: $F(3,33)=23.92$, $p<.001, \eta^{2}=.79$ and $F(2,34)=36.82, p<.001, \eta^{2}=.69$ respectively, Completer: $F(3,28)=$ 22.66, $p<.001, \eta^{2}=.71$, and $F(3,28)=40.58, p<.001, \eta^{2}=.81$, respectively (see Figure 3 , right panels). However, there were no significant main effects of Group or Time $\times$ Group interactions either during or following OST (i.e., to three-month follow-up) in either ITT or completer analyses, all $F<1.30$, all $p>.29$.

\section{Change on Diagnostic and Symptom Measures across Time}


Diagnostic status. Based on ITT and completer analyses, there were no significant group differences in diagnostic outcomes at post-treatment, all $\chi^{2}{ }_{1}<3.31$, all $p>.07$, or at three-month follow-up, all $\chi^{2}{ }_{1}<2.76$, all $p>.74$ (see Table 3). At post-treatment, $31 \%$ of the ATP+OST group and 25\% in the ATC+OST group did not meet diagnostic criteria for their phobic disorder at post-treatment; 25\% of children in each group no longer met criteria for their principal diagnosis at post-treatment; $19 \%$ of children in the ATC+OST group and 0\% of children in the ATP+OST group no longer met criteria for any anxiety diagnoses. By three-month follow-up, $62 \%$ and $75 \%$ of the ATP+OST and ATC+OST groups respectively, did not meet criteria for their phobic diagnosis or principal diagnosis, and 50\% and 62\% respectively, no longer met criteria for any anxiety diagnosis.

Similarly, both ITT and completer analyses of change in number of diagnoses revealed significant main effects of Time, $F(2,34)=17.23, p<.001, \eta^{2}=.50$, and $F(2,29)=$ 23.97, $p<.001, \eta^{2}=.62$ respectively, but no other significant effects, all $F$ 's $<2.13$, all $p>$ .15. Number of diagnoses was not significantly lower at post- compared to pre-treatment in either analysis (both $p>$.09), but were significantly lower at three-month follow-up compared to pre-treatment (both $p<.001$ ), and post-treatment (both $p<.001$ ) (see Table 3). Insert Table 3

Severity of phobic and principal diagnoses. The Time $\times$ Group mixed factorial ANOVAs of CSRs for phobic and principal diagnoses revealed significant main effects of Time on both ITT and completer analyses, ITT: $F(2,34)=44.77, p<.001, \eta^{2}=.71$, and $F(2$, $34)=51.62, p<.001, \eta^{2}=.75$ respectively, Completer: $F(2,29)=59.56, p<.001, \eta^{2}=.80$ and $F(2,29)=70.52, p<.001, \eta^{2}=.83$ respectively, but no other significant effects, all $F$ 's $<$ .50 , all $p>$.49. In each group, ITT and completer analyses confirmed that CSRs of both types of diagnoses reduced significantly from pre- to post-treatment (all $p<.001$ ) and from pre- to three-month follow-up (all $p<.001)$ (see Table 3). 
Anxiety symptom severity. For ITT and completer analyses, the Time x Group mixed factorial ANOVA of SCAS-P total scores revealed significant main effects of Time, $F(2,34)$ $=26.04, p<.001, \eta^{2}=.61$ and $F(2,22)=23.74, p<.001, \eta^{2}=.68$ as well as significant Time $\times$ Group interactions, $F(2,34)=3.81, p=.032, \eta^{2}=.18$ and $F(2,22)=3.82, p=.038, \eta^{2}=$ .26 respectively. The interactions were due to the significant Group differences at pretreatment for ITT and completer samples, (both $p<.02$ ), but no significant group difference at post-treatment or at three-month follow-up (all $p>$.27). The Time $\times$ Group mixed factorial ANOVA of SCAS-C total scores based on ITT and completer analyses found significant main effects of Time, $F(2,34)=27.92, p<.001, \eta^{2}=.62$ and $F(2,23)=24.08, p<.001, \eta^{2}=$ .68 respectively, reflecting that, in each group, SCAS-C total scores declined significantly from pre- to post-treatment (all $p<.015$ ) and from pre- to three-month follow-up (all $p<$ .001) (see Table 3).

Depression symptom severity and global functioning. The Time $\times$ Group mixed factorial ANOVAs of SMFQ-P, SMFQ-C, and CGAS total scores based on ITT and completer analyses revealed significant main effects of Time, SMFQ-P: $F(2,34)=6.56, p=$ $.004, \eta^{2}=.28$ and $F(2,22)=8.53, p=.002, \eta^{2}=.46$, SMFQ-F: $F(2,34)=10.73, \mathrm{p}<.001, \eta^{2}$ $=.39$ and $F(2,23)=5.37, \mathrm{p}=.013, \mathrm{\eta}^{2}=.34$, and CGAS: $F(2,34)=19.74, \mathrm{p}<.001, \mathrm{\eta}^{2}=.54$ and $F(2,29)=28.69, \mathrm{p}<.001, \mathrm{\eta}^{2}=.66$, respectively, but no other significant effects, all $F$ 's $<3.80$, all $p>$.058 (see Table 3). SMFQ-C and SMFQ-P scores declined significantly from pre- to post-treatment (both $p<.05$ ) and to three-month follow-up (both $p<.05$ ), but differences between post-treatment and three-month-follow-up were not significant (both $p>$ .50). CGAS scores increased significantly from pre- to post-treatment in ITT and completer analyses (both $\mathrm{p}<.001$ ) and from pre- to three-month follow-up (both $p<.018$ ).

Prediction of Three-Month Follow-up Phobia Diagnosis Severity by Post-Treatment Attention Bias for Happy Faces 
To consider whether post-treatment attention bias towards positive stimuli predicted improvement in phobia diagnostic severity three-months following treatment (e.g., Reinecke et al., 2013), treatment group status and happy face bias scores were first examined as correlates of phobia outcome at three-month follow-up. In this regression model, group (ATP+OST or ATC+OST), post-treatment happy face bias score, and a group x bias interaction term were entered as independent variables. Three-month follow-up phobia diagnosis CSR was the dependent variable. Pre- and post-treatment phobia diagnosis CSRs were also entered in the first step to control for their influence. The model accounted for $22 \%$ of variance in three-month follow-up phobia diagnosis CSRs, $F(4,27)=5.30, p=.03$. In this model, the Group $\times$ Happy face bias score interaction was significant, $\Delta R^{2}=.13, F(1,27)=$ 4.58, $p=.05, \beta=-.17, \mathrm{SE}=.025, B=-.63$.

Two follow-up regressions (one for each group) were estimated to decompose this interaction (see Figure 4). In the ATP+OST group, post-treatment happy face bias scores were a significant predictor of three-month follow-up phobia CSRs (taking account of preand post-treatment CSRs), $\Delta R^{2}=.25, F(1,14)=4.53, p=.05$, with those children showing greater vigilance for happy faces at post-treatment achieving lower phobic disorder severity at three-month follow-up (see Figure 4). In contrast, post-treatment happy face bias scores were not predictive of follow-up phobia disorder CSRs in the ATC+OST group, $\Delta R^{2}=.07$, $F(1,14)=0.40, p=.63$ (see Figure 4).

Insert Figure 4

\section{Discussion}

This study examined whether treatment outcomes from one session of intensive exposure therapy could be enhanced by training children to direct attention to positive stimuli. Findings revealed partial support for the hypotheses. In comparison to the control condition, training attention towards positive stimuli prior to the OST significantly increased 
attention to happy faces at post-treatment assessment, and produced significantly larger and faster reductions in danger expectancies throughout the OST. These improvements were maintained at the three-month follow-up assessment. Despite these promising findings of group differences in cognitive mechanisms, the ATP+OST condition did not produce better clinical outcomes in terms of phobia diagnostic severity, symptom reduction or global functioning at post-treatment or three-month follow-up compared to the ATC+OST condition. However, the regression analyses suggested that children who had a greater posttreatment attention bias towards happy faces following ATP+OST were more likely to show lower levels of phobia diagnosis severity at three-month follow-up assessment compared to the ATC+OST condition.

Since changes in attention bias towards positive stimuli and danger expectancies were specific to the ATP+OST condition, the findings suggest that ATP was effective in altering both implicit and explicit cognitive processes over and above OST. However, that both conditions produced similar improvements in clinical outcomes of magnitudes that are comparable to previous studies of OST with children (e.g., Muris et al., 1998; Ollendick et al., 2009; Öst et al., 2001), suggests that a single “dose” of 160 trials of ATP failed to enhance therapeutic outcomes beyond that achieved by OST. In accord, ATP had no significant effect on state anxiety or positive mood, whereas significant improvements were observed after the OST in both conditions. Although these findings fail to support the main hypotheses, it is possible that clinical benefits in favour of ATP might be observed if the dose of ATP prior to OST was stronger. It is noteworthy that studies finding clinical benefits of ATP have included many more trials and/or sessions compared to the present study, e.g., 744 trials over 4 sessions (e.g., Heeren et al., 2012), 384 trials in a single session (e.g., Taylor et al., 2011), 1920 trials over 12 sessions (e.g., Waters et al., 2013). Thus, a stronger dose of ATP might enhance clinical outcomes beyond those achieved by OST. 
The current study did find that ATP+OST was effective in improving attention deployment to happy faces compared to the ATC+OST condition, consistent with some ABMT studies (De Voogd et al., 2014; Heeren et al., 2012; Taylor et al., 2011; Waters et al., 2013). As both conditions involved the same exposure to angry and happy face pairs, the findings suggest that active training of attention towards happy faces and not mere exposure to positive stimuli produced this change in attention deployment.

It is noteworthy that the present study trained attention to happy faces using happyangry face pairs during ATP and assessed attention bias to another set of face stimuli using happy-neutral and angry-neutral face pairs. Given that the present sample as a whole did not show a marked pre-treatment attention bias towards threat stimuli, similar to findings from other studies (e.g., Bechor et al., 2013; Cowart \& Ollendick, 2011; Rapee et al., 2013), it seems unlikely that ATP could significantly impact attention to threat. Rather, similar to some previous ABMT studies (e.g., De Voogd et al., 2014; Waters et al., 2013), the present study found that ATP increased attention towards happy faces (even though different stimulus sets and stimulus pairings were used in training and assessment of bias). Thus, as ATP enhanced attention bias to positive stimuli which generalised to other stimulus sets (i.e., post-treatment visual probe task), it is possible that the induced positive bias may also have generalised to other contexts (e.g. increasing attention to positive aspects of the exposure session).

The present findings also suggest that ATP prior to OST produced faster and larger reductions in danger expectancies during the OST and at three-month follow-up assessment compared to the control condition. Previous ABMT studies have not assessed changes in explicit cognitive biases as a stand-alone outcome measure of ABMT or during stressor tasks before and after ABMT (i.e., somewhat akin to the OST following ABMT in the present study). As suggested earlier, ATP may influence danger expectancies by encouraging children to focus attention on safe aspects of the exposure session (such as evidence that the 
phobic stimulus is objectively harmless), which may be particularly important in promoting the effectiveness of OST, in terms of disconfirming feared outcomes (Craske et al., 2008). Although there was no significant effect of ATP on coping expectancies, it is possible that ATP heightened the activation of positive thoughts and emotions which in turn contributed to more positive appraisals of the situation/objects that participants subsequently dealt with during the OST. However, state anxiety and positive affect did not differ between groups or change significantly from pre- to post-attention training suggesting that differences between conditions during OST were not due to ATP priming affective responses (Forgas, 2001). There was also no support for the proposal that ATP might have a beneficial effect on treatment by reducing attentional bias for negative information, as there was no significant effect of attention training on the negative bias index. Another possibility, noted earlier, is that ATP activates approach motivation, which not only prioritises processing of rewardrelated information and supports approach behaviours, but also may offset avoidance that is likely to interfere with exposure therapy. Studies that undertake more fine-grain analyses of change in both danger expectancies and behavioural approach tendencies (e.g., standardised behavioural approach task, or experimental approach-avoidance tasks, Krieglmeyer \& Deutsch, 2010) during OST would help clarify these potential underlying mechanisms. Moreover, the present findings showed that those children receiving ATP+OST who showed stronger attention deployment to positive stimuli at post-treatment assessment achieved a lower level of clinician-rated phobia diagnostic severity at three-month follow-up. No such significant association was found for the ATC+OST condition. Children in the present study who developed stronger attention biases to positive stimuli following ATP+OST may have been particularly well-suited to this type of treatment; i.e. learning to increase their attention focus on positive cues, and using this as a means to regulate fear when re-encountering their phobic object/situation during the follow-up period. This may relate to why the predictive effect of attention bias towards positive stimuli was observed specifically 
on phobia diagnosis severity and not other outcome measures at the follow-up assessment. It will be important in future studies with larger samples sizes to examine the predictive effects of combinations of cognitive mechanisms on clinical outcomes (e.g., attention deployment x danger expectancies).

In addition to sample sizes and the relatively small "dose” of ATP, the study had other limitations. While the groups did not differ before treatment on the primary measures of phobic severity or other symptoms, there was one exception which was, by chance, parentreport of general anxiety symptoms. Thus, it would seem informative for future research to examine whether the effectiveness of ATP may differ as a function of the child's pretreatment anxiety symptom severity (e.g. whether children with greater anxiety symptoms may benefit more from ATP). The present study utilised face stimuli during attention training because faces have broad ecological validity and the utilisation of the same standardised stimulus set in both ATP and ATC provides necessary experimental control (Waters et al., 2008). Future studies should examine whether ATP enhances outcomes from OST when the training stimuli are more closely matched to the type of phobia and stimuli used during the OST (i.e. tailored to each participant's fears), although this may be more time- and resourceintensive and limit the generalizability of findings. Also, attention bias could not be assessed between attention training and the OST, because this could have altered the face-probe contingency established during attention training (i.e., when assessing bias, there is no systematic relationship between the positions of the emotional faces and probes, which may weaken the effect of the preceding ATP). Consequently, it was not possible to determine the temporal relationship between the development of a positive attention bias and reduction in danger expectancies during OST. Therefore, the extent of change and association between implicit and explicit cognitive mechanisms over time could not be determined.

Despite these limitations, the present study found that attention training to positive stimuli prior to one session of intensive exposure therapy reduced children's danger 
expectancies about feared situations/objects and increased attention to positive stimuli compared to the control condition, which in turn, predicted lower levels of clinician-rated phobia diagnostic severity three-months after treatment. The present study did not find that attention training to positive stimuli prior to intensive exposure therapy produced greater improvements in clinician, parent, or child-rated clinical outcomes relative to the control condition. However, future studies with larger sample sizes that utilise a stronger "dose” of attention training towards positive stimuli may find greater clinical benefits of attention training to positive stimuli. 


\section{Footnotes}

All analyses with pre-treatment SCAS-P total scores included as a covariate revealed no significant effects involving the covariate and are not reported further. 


\section{Acknowledgements}

This research was supported by a Griffith University Areas of Strategic Investment in

Chronic Disease Prevention Grant awarded to the authors. Thanks are due to the Study Coordinator, Ms Emily Allen, and the team of clinicians who worked on this project. 


\section{References}

Amir, N., Weber, G., Beard, C., Bomyea, J., \& Taylor, C.T., 2008. The effect of a singlesession attention modification program on response to a public-speaking challenge in socially anxious individuals. Journal of Abnormal Psychology, 117, 860-868.

Amir, N., Beard, C., Burns, M., \& Bomyea, J., 2009. Attention modification program in individuals with generalized anxiety disorder. Journal of Abnormal Psychology, 118, 28-33.

Amir, N., Beard, C., Taylor, C. T., Klumpp, H., Elias, J., Burns, M., \& Chen, X. (2009). Attention training in individuals with generalized social phobia: A randomized controlled trial. Journal of Consulting and Clinical Psychology, 77, 961-973.

Amir, N., \& Taylor, C. T. (2012). Combining computerized home-based treatments for generalized anxiety disorder: An attention modification paradigm and cognitive behavioral therapy. Behavior Therapy, 43, 456-459.

Angold, A., Costello, E. J., \& Messer, S. C. (1995). Development of a short questionnaire for use in epidemiological studies of depression in children and adolescents. International Journal of Methods in Psychiatric Research, 5, 237-249.

Bar-Haim, Y., Morag, I., \& Glickman, S., 2011. Training anxious children to disengage attention from threat: a randomized controlled trial. Journal of Child Psychology and Psychiatry and Allied Disciplines, 52, 861-869.

Bar-Haim, Y., Lamy, D., Pergamin, L., Bakermans-Kranenburg, M. J., \& Van-Ijzendoorn, M. H. (2007). Threat-related attentional bias in anxious and non- anxious individuals: a meta-analytic study. Psychological Bulletin, 133, 1-24.

Bechor, M., Pettit, J. W., Silverman, W. K., Bar-Haim, Y., Abend, R., Pine, D. S., \& Vasey, M. W. (2013). Bias modification treatment for children with anxiety disorders who do not respond to cognitive behavioral therapy: A case series. Journal of Anxiety Disorders. http://dx.doi.org/doi:10.1016/j.janxdis.2013.09.001 
Behar, E., McHugh, R. K., Peckham, A., \& Otto, M. W. (2010). D-cycloserine for the augmentation of an attentional training intervention for trait anxiety. Journal of Anxiety Disorders, 24, 440-445.

Boschen, M. J., Neumann, D. L., \& Waters, A. M. (2009). Relapse of successfully treated anxiety and fear: Theoretical issues and recommendations for clinical practice. Australian and New Zealand Journal of Psychiatry. 43, 89-100.

Bouton, E. (2002). Context, ambiguity, and unlearning: Sources of relapse after behavioural extinction. Journal of Biological Psychiatry, 52, 976-986.

Boyatzis, C. J., Chazan, E., \& Ting, C. Z. (1993). Preschool children’s decoding of facial emotions. Journal of Genetic Psychology, 154, 375-382.

Bradley, B. P., Mogg, K., Falla, S. J., \& Hamilton, L. R. (1998). Attentional bias for threatening facial expressions in anxiety: Manipulation of stimulus duration. Cognition and Emotion, 12, 737-753.

Chambless, D. L., \& Ollendick, T. H. (2001). Empirically supported psychological interventions: Controversies and evidence. Annual Review of Psychology, 52, 685-716.

Clarke, P., MacLeod, C., \& Shirazee, N. (2008). Prepared for the worst: Readiness to acquire threat bias and susceptibility to elevate trait anxiety. Emotion, 8, 47-57.

Cowart, M. J. W., \& Ollendick, T. H. (2011). Attention training in socially anxious children: a multiple baseline design analysis. Journal of Anxiety Disorders 25, 972-977.

Craske, M. G., Kircanski, K., Zelikowsky, M., Mystkowski, J., Chowdhury, N., \& Baker, A. (2008). Optimizing inhibitory learning during exposure therapy. Behaviour Research and Therapy, 46, 5-27.

Crocker, L. D., Heller, W., Warren, S. L., O’Hare, A. J., Infantolino, Z. P.., \& Miller, G. A. (2013). Relationships among cognition, emotion and motivation: Implications for intervention and neuroplasticity in psychopathology. Frontiers in Human Neuroscience, 7, 261. 
Dandeneau, S. D., Baldwin, M. W., Baccus, J. R., Sakellaropoulo, M., \& Pruessner, J. C. (2007). Cutting stress off at the pass: reducing vigilance and responsiveness to social threat by manipulating attention. Journal of Personality and Social Psychology, 93, $651-666$.

Davis, T. E., III, \& Ollendick, T. H. (2005). A critical review of empirically supported treatments for specific phobias in children: Do efficacious treatments address the components of a phobic response? Clinical Psychology: Science and Practice, 12, $144-$ 160.

De Voogd, E. L., Wiers, R. W., Prins, P. J. M., \& Salemink, E. (2014). Visual search attentional bias modification reduced social phobia in adolescents. Journal of Behavior Therapy and Experimental Psychiatry, 42, 252-259.

Eldar, S., Apter, A., Lotan, D., Edgar, K. P., Naim, R., Fox, N. A., Pine, D. S., \& BarHaim,Y. (2012). Attention bias modification treatment for paediatric anxiety disorders: A randomised controlled trial. American Journal of Psychiatry, 169, 213-220.

Eldar, S., \& Bar-Haim, Y. (2010). Neural plasticity in response to attention training in anxiety. Psychological Medicine, 40, 667-677.

Essau, C. A. (2005). Use of mental health services among adolescents with anxiety and depressive disorders. Depression and Anxiety, 22, 130-137.

Farrell, L. J., Waters, A. M., Milliner, E., \& Ollendick, T. (2012). Comorbidity and treatment response in paediatric OCD: Outcomes of group cognitive behavioural therapy. Psychiatry Research. 199, 115-123.

Forgas, J. (2001). The affect infusion model (AIM): An integrative theory of mood effects on cognition and judgments. In L. Martin \& G. L. Clore (Eds.), Theories of mood and cognition: A user's guidebook (pp. 99-143). Mahwah, NJ: Erlbaum. 
Ginsburg, G. S., Becker, E. M., Keeton, C. P., Sakolsky, D., Piacentini, J., Albano, A. M., Compton, S. N., Iyengar, S., Sullivan, K., Caporino, N., Peris, T., Birmaher, B., Rynn, M., March, J., \& Kendall, P. C. (2014). Naturalistic Follow-up of Youths Treated for Pediatric Anxiety Disorders. JAMA Psychiatry. 71(3), 310-318.

Gosselin, P., \& Larocque, C. (2000). Facial morphology and children’s categorization of facial expressions of emotions: A comparison between Asian and Caucasian faces. Journal of Genetic Psychology, 161, 346-358.

Gregory, A. M., Caspi, A., Moffitt, T. E., Koenen, K., Eley, T. C., \& Poulton, R. (2007). Juvenile mental health histories of adults with anxiety disorders. American Journal of Psychiatry, 164, 301-308.

Gross, J. J., \& Thompson, R. A. (2007). Emotion regulation conceptual foundations. In J. J. Gross (Ed.), Handbook of emotion regulation (pp. 3-24). New York: Guillford Press.

Hakamata, Y., Lissek, S., Bar-Haim, Y., Britton, J. C., Fox, N. A., Leibenluft, E., Ernst, M., \& Pine, D. S. (2010). Attention bias modification treatment: a meta-analysis toward the establishment of novel treatment for anxiety. Biological psychiatry, 68(11), 982-990.

Hallion, L. S., \& Ruscio, A. M. (2011). A meta-analysis of the effect of cognitive bias modification on anxiety and depression. Psychological Bulletin, 137(6), 940-958.

Hazen, R. A.,Vasey, M. W., \& Schmidt, N. B. (2009).Attentional retraining: A randomized clinical trials for pathological worry. Journal of Psychiatric Research, 43, 627-633.

Heeren, A., Lievens, L., \& Philippot, P. (2011). How does attention training work in social phobia: disengagement from threat or re-engagement to non-threat? Journal of Anxiety Disorders, 25(8), 1108-1115.

Heeren, A., Reese, H. E., McNally, R. J., \& Philippot, P. (2012). Attention training toward and away from threat in social phobia: Effects on subjective, behavioral, and physiological measures of anxiety. Behaviour Research and Therapy, 50(1), 30-39. 
Ialongo, N., Edelsohn, G., Werthamer-Larsson, L., Crockett, L., \& Kellam, S. (1995). The significance of self-reported anxious symptoms in first grade children: Prediction to anxious symptoms and adaptive functioning in fifth grade. Journal of Child Psychology and Psychiatry, 36, 427-437.

Johnson, D.R. (2009). Goal-directed attentional deployment to emotional faces and individual differences in emotion regulation. Journal of Research in Personality, 43, 8-13.

Julian, K., Beard, C., Schmidt, N. B., Powers, M. B., \& Smits, J. A. J. (2012). Attention training to reduce attention bias and social stressor reactivity: An attempt to replicate and extend previous findings. Behaviour Research and Therapy, 50(5), 350-358.

Kendall, P. C., Safford, S., Flannery-Schroeder, E. C., \& Webb, A. (2004). Child anxiety treatments: Outcomes in adolescence and impact on substance use and depression at 7.4 year follow-up. Journal of Consulting and Clinical Psychology, 72, 276-287.

Kessler, R. C., Berglund, P., Demler, O., Jin, R., Merikangas, K. R., \& Walters, E. E. (2005). Lifetime prevalence and age-of-onset distributions of DSM-IV disorders in the national comorbidity survey replication. Archives of General Psychiatry, 62, 593-602.

Kendall, P. C., Settipani, C. A., \& Cummings, C. M. (2012). No need to worry: The promising future of child anxiety research. Journal of Clinical Child \& Adolescent Psychology, 41, 103-115.

Krieglmeyer, R., \& Deutsch, R. (2010). Comparing measures of approach-avoidance behaviour: The manikin task vs. two versions of the joystick task. Cognition and Emotion, 24(5), 810-828

Lyneham, H. J., \& Rapee, R. M. (2005). Agreement between telephone and in-person delivery of a structured interview for anxiety disorders in children. Journal of the American Academy of Child and Adolescent Psychiatry, 44(3), 274-282.

MacLeod, C., Mathews, A., \& Tata, P. (1986). Attentional bias in emotional disorders. Journal of Abnormal Psychology, 95, 15-20. 
McNally, R. J., Enock, P. M., Tsai, C., \& Tousian, M. (2013). Attention bias modification for reducing speech anxiety. Behaviour Research and Therapy, 51, 882-888.

Monk, C.S., Nelson, E. E., McClure, E. B., Mogg, K., Bradley, B. P., Leibenluft, E., Blair, J. R., Chen, G., Charney, D. S., Ernst, M., \& Pine, D. S. (2006). Ventrolateral prefrontal cortex activation and attentional bias in response to angry faces in adolescents with generalized anxiety disorder. The American Journal of Psychiatry, 163, 1091-1097.

Muris, P., Merckelbach, H., Holdrinet, I., \& Sijsenaar, M. (1998). Treating phobic children: Effects of EMDR versus exposure. Journal of Consulting and Clinical Psychology, 66, 193-198.

Nauta, M. H., Scholing. A., Rapee, R. M., Abbott, M., Spence, S. H., \& Waters, A. (2004). A parent- report measure of children’s anxiety: psychometric properties and comparison with child-report in a clinic and normal sample. Behaviour Research and Therapy, 42, 813-839.

Neubauer, K., von Auer, M., Murray, E., Petermann, F., Helbig-Lang, S. \& Gerlach, A. L. (2013). Internet-delivered attention modification training as a treatment for social phobia: A randomized controlled trial. Behaviour Research and Therapy, 51, 87-97.

Ollendick, T. H., Hagopian, L. P., \& King, N. J. (1997). Specific phobias in children. In G. C. L. Davey (Ed.), Phobias: A handbook of theory, research and treatment (pp. 201-223). London: John Wiley \& Sons.

Ollendick, T. H., \& March, J. S. (Eds.). (2004). Phobic and anxiety disorders in children and adolescents: A clinician's guide to effective psychosocial and pharmacological interventions. New York: Oxford University Press.

Ollendick, T. H., King, N. J., \& Chorpita, B. F. (2006). Empirically supported treatments for children and adolescents. In P. C. Kendall (Ed.), Child and adolescent therapy: Cognitive-behavioral procedures (3rd ed., pp. 492-520). New York: Guilford Press. 
Ollendick, T. H., Öst, L-G., Reuterskoild, L., Costa, N., \& Cederland, R. (2009). One session treatment of specific phobias in youth: A randomized clinical trial in the United States and Sweden. Journal of Consulting and Clinical Psychology, 77, 505-516.

Öst, L.-G. (1997). Rapid treatment of specific phobias. In G. C. L. Davey (Ed.), Phobias: A handbook of theory, research and treatment (pp. 227-247). Oxford, England: Wiley.

Öst, L.-G., \& Ollendick, T. H. (2001). Manual for one-session treatment of specific phobias. Unpublished manuscript. (Available from the Phobia Project, Child Study Center, Virginia Tech, Blacksburg, VA 24060).

Öst L.-G., Svensson, L., Hellstrom, K., \& Lindwall, R. (2001). One session treatment of specific phobias in youths: A randomized clinical trial. Journal of Consulting and Clinical Psychology, 69, 814-824.

Pessoa, L. (2009). How do emotion and motivation direct executive control? Trends in Cognitive Sciences, 13(4), 160-166.

Pine, D. S., Mogg, K., Bradley, B. P., Montgomery, L., Monk, C. S., McClure, E., Guyer, A. E., Ernst, M., \& Charney, D. S., \& Kaufman, J. (2005). Attention bias to threat in maltreated children: Implications for vulnerability to stress-related psychopathology. The American Journal of Psychiatry, 162, 291-296.

Rapee, R. M., Schniering, C., \& Hudson, J. L. (2009). Anxiety disorders during childhood and adolescents: Origins and treatment. Annual Review of Clinical Psychology, 5, 311341.

Rapee, R. M., MacLeod. C., Carpenter, L., Gaston, J. E., Frei, J., Peters, L., \& Baillie, A. J. (2013). Integrating cognitive bias modification into a standard cognitive behavioural treatment package for social phobia: A randomized controlled trial. Behaviour Research and Therapy, 51, 207-215. 
Reinecke, A., Waldenmaier, L., Cooper, M. J., \& Harmer, C. J. (2013). Changes in automatic threat processing precede and predict clinical changes with exposure-based cognitivebehavior therapy for panic disorder. Biological Psychiatry, 73, 1064-1070.

Rozenman, M., Weersing, R., \& Amir, N. (2011). A case series of attention modification in clinically anxious youths. Behaviour Research and Therapy 49, 324-330.

Salum, G. A., Mogg, K., Bradley, B. P., Gadelh, A., Pan, P., Tamanaha, A. C.,... Pine, D. S. (2012). Threat bias in attention orienting: Evidence of specificity in a large communitybased study. Psychological Medicine, 1(1), 1-13.

Shaffer, D., Gould, M. S., Brasic, J., Ambrosini, P., Fisher, P., Bird, H., Aluwahlia, S. (1983). A Children's Global Assessment Scale (CGAS). Archives of General Psychiatry. 40, $1228-1231$.

Schmidt, N. B., Richey, J. A., Buckner, J. D., \& Timpano, K. R. (2009). Attention training for generalized social anxiety disorder. Journal of Abnormal Psychology, 118, 5-14.

See, J., MacLeod, C., \& Bridle, R. (2009). The reduction of anxiety vulnerability through the modification of attentional bias: A real-world study using a home-based cognitive bias modification procedure. Journal of Abnormal Psychology, 118, 65-75.

Shechner, T., Rimon-Chakir, A., Britton, J. C., Lotan, D., Apter, A., Bliese, P. D., Pine, D. S., \& Bar-Haim, Y. (2014). Attention bias modification treatment augmenting effects on cognitive behavioural therapy in children with anxiety: Randomized controlled trial. Journal of the American Academy of Child and Adolescent Psychiatry, 53, 61-71.

Silverman, W. K., \& Albano, A. M. (1996). Anxiety Disorders Interview Schedule for DSMIV: Child and Parent Versions. San Antonio, TX: Psychological Corporation.

Silverman, W. K., Saavedra, L. M., \& Pina, A. A. (2001). Test-retest reliability of anxiety symptoms and diagnoses with the Anxiety Disorders Interview Schedule for DSM-IV: Child and parent versions. Journal of American Academy of Child and Adolescent Psychiatry. 40, 937-944. 
Spence, S. H. (1998). A measure of anxiety symptoms among children. Behaviour Research and Therapy. 36, 545-566.

Spence, S. H., Holmes, J. M., March, S., \& Lipp, O. V. (2006). The feasibility and outcome of clinic plus internet delivery of cognitive-behavior therapy for childhood anxiety. Journal of Consulting and Clinical Psychology. 74, 614-621.

Spielberger, C. D. (1973). Manual for the State-Trait Anxiety Inventory for Children. Palo Alto, CA: Consulting Psychologists Press.

Stinson, F. S., Dawson, D. A., Chou, S. P., Smith, S., Goldstein, R. B., Ruan, W. J., et al. (2007). The epidemiology of DSM-IV specific phobia in the USA: Results from the National Epidemiologic Survey on Alcohol and Related Conditions. Psychological Medicine, 37, 1047-1059.

Taylor, C.T., Bomyea, J., \& Amir, N. (2011). Malleability of attentional bias for positive emotional information and anxiety vulnerability. Emotion, 11, 127-138.

Tottenham, N., Tanaka, J., Leon, A.C., McCarry, T., Nurse, M., Hare, T.A., Marcus, D.J., Westerlund, A., Casey, B.J., Nelson, C. (2009). The NimStim set of facial expressions: Judgments from untrained research participants. Psychiatry Research, 168, 242-249.

Van Bockstaele, B., Verschuere, B., De Houwer, J., \& Crombez, G. (2010). On the costs and benefits of directing attention towards or away from threat-related stimuli: A classical conditioning experiment. Behaviour Research and Therapy, 48(7), 692-697.

Vervliet, B., Craske, M. G., \& Hermans, D. (2012). Fear extinction and relapse: State of the art. Annual Review of Clinical Psychology, 9, 215-248.

Wadlinger, H. A., \& Isaacowitz, D. M. (2008). Looking happy: The experimental manipulation of a positive visual attention bias. Emotion, 8, 121-126.

Waters, A. M., Mogg, K., Bradley, B. P., \& Pine, D. S. (2008). Attentional bias for emotional faces in children with generalised anxiety disorder. Journal of the American Academy of Child and Adolescent Psychiatry, 47(4), 435-442. 
Waters, A. M., Wharton, T. A., Craske, M. G., \& Zimmer-Gembeck, M. J. (2008). Threatbased cognitive biases in anxious children: Comparison with non-anxious children before and after cognitive-behavioural treatment. Behaviour Research and Therapy. 46(3), 358-374.

Waters, A. M., Ford, L. A., Wharton, T. A., \& Cobham, V. E. (2009). Cognitive behavioural therapy for young children with anxiety disorders: Comparison of group-based child + parent versus parent only focused treatment. Behaviour Research and Therapy. 47, 654-662.

Waters, A. M., Pittaway, M., Mogg, K., Bradley, B. P., \& Pine, D. (2013). Attention training to positive stimuli in childhood anxiety disorders. Developmental Cognitive Neuroscience. 4, 77-84.

Waters, A. M., Farrell, L. J., \& Schilpzand, E. (2013). Neuropsychological assessment and clinical intervention for youth with anxiety disorders. In L.A. Reddy, A.Weissman. \& J.B., Hale (Ed.), Neuropsychological assessment and intervention for youth: An evidence-based approach to emotional and behavioral disorders. American Psychological Association Press: Washington DC. pp. 13-40.

Waters, A. M., Bradley, B. P., \& Mogg, K. (2014). Biased attention to threat in paediatric anxiety disorders (generalized anxiety disorder, social phobia, specific phobia, separation anxiety disorder) as a function of “distress” versus “fear” disorder categorization. Psychological Medicine. 44, 607-616.

Wood, J., Piacentini, J. C., Bergman, R. L., McCracken, J., \& Barrios, V. (2002). Concurrent validity of the anxiety disorders section of the anxiety disorders interview schedule for DSM-IV: Child and parent versions. Journal of Clinical Child and Adolescent Psychology, 31, 335-342.

Zlomke, K., \& Davis, T. E., III. (2008). One-session treatment of specific phobias: A detailed description and review of treatment efficacy. Behavior Therapy, 39, 207-223. 
Table 1: Socio-demographic and symptom information as a function of group based on intent-to-treat and completer samples

\begin{tabular}{lllll}
\hline & ATP+OST & ATC+OST & ATP+OST & ATC+OST \\
\cline { 2 - 5 } Measure & Intent-to-Treat & & Completer & \\
\cline { 2 - 5 } & $(\mathrm{N}=19)$ & $(\mathrm{N}=18)$ & $(\mathrm{N}=16)$ & $(\mathrm{N}=16)$ \\
\hline Gender M:F & $11: 8$ & $5: 13$ & $10: 6$ & $6: 10$ \\
Age Y:M & $10.06(2.89)$ & $11.05(2.59)$ & $10.08(3.01)$ & $10.07(2.69)$ \\
\% Born Australia & 93 & 83 & 92 & 81 \\
\% Parents Married & 63 & 78 & 81 & 87 \\
\% Parent Tertiary & & & & \\
Educated & & & & 75 \\
$\quad$ Mother & 58 & 67 & 57 & 68 \\
$\quad$ Father & 48 & 88 & 92 & 81 \\
\% Family Income & 85 & $27.67(19.61)$ & $35.35(15.99)$ & $28.75(20.05)$ \\
$\quad$ \$80,000 and above & $35.89(16.12)$ & $23.44(15.78)$ & $34.81(13.73)$ & $22.38(15.41)$ \\
SCAS-C Total Score & $35.11(12.86)$ & $5.11(4.24)$ & $4.06(3.66)$ & $5.44(4.38)$ \\
SCAS-P Total Score & $4.16(3.58)$ & $2.61(2.83)$ & $4.19(2.97)$ & $2.69(2.99)$ \\
SMFQ-C Total Score & $4.21(2.92)$ & $62.06(10.20)$ & $56.63(8.58)$ & $61.06(10.64)$ \\
SMFQ-P Total Score & $56.89(8.10)$ & & & \\
CGAS (0-100) & &
\end{tabular}




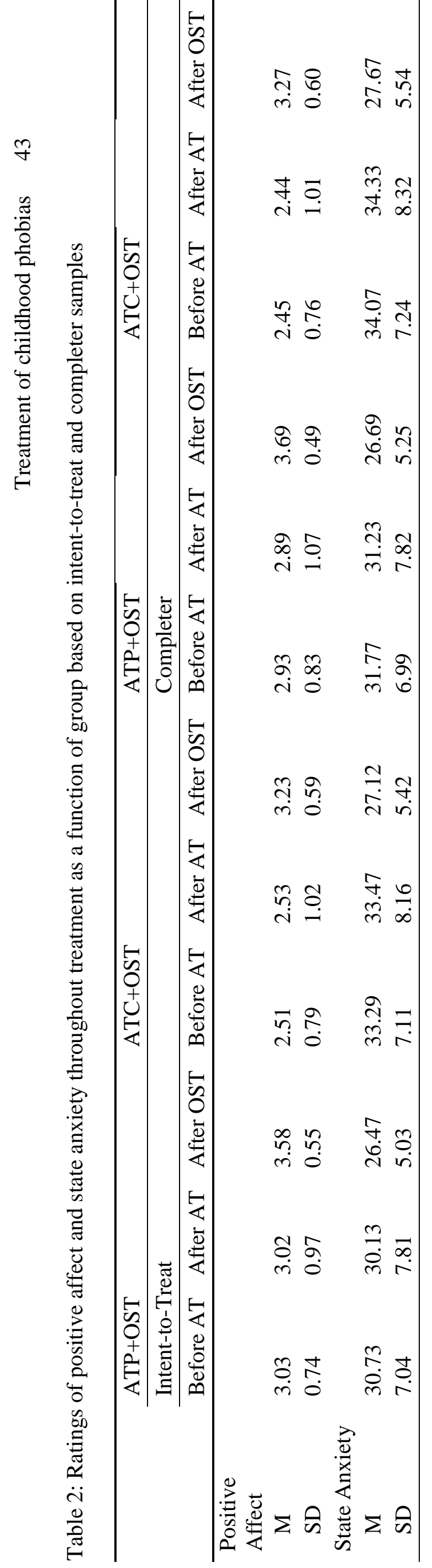




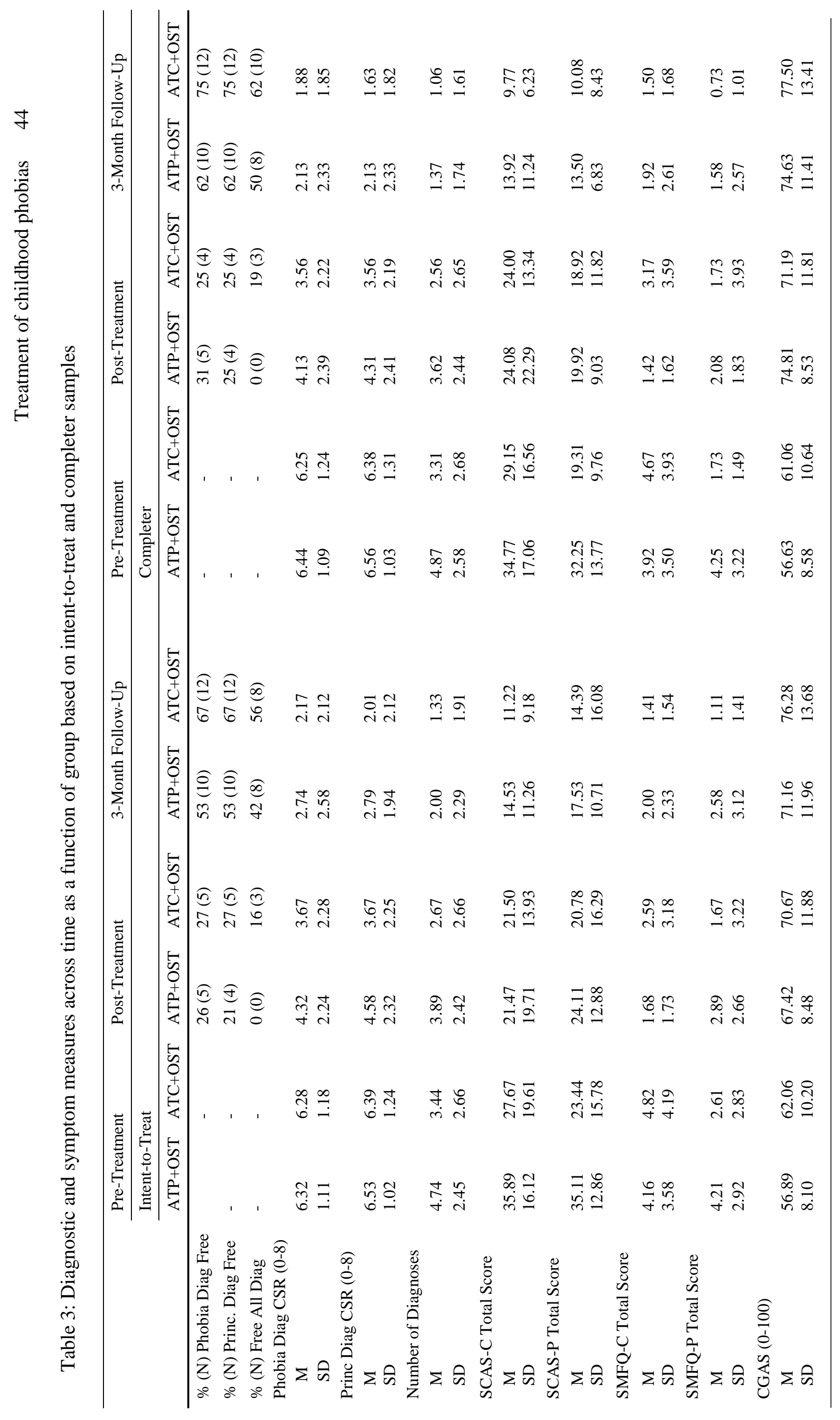




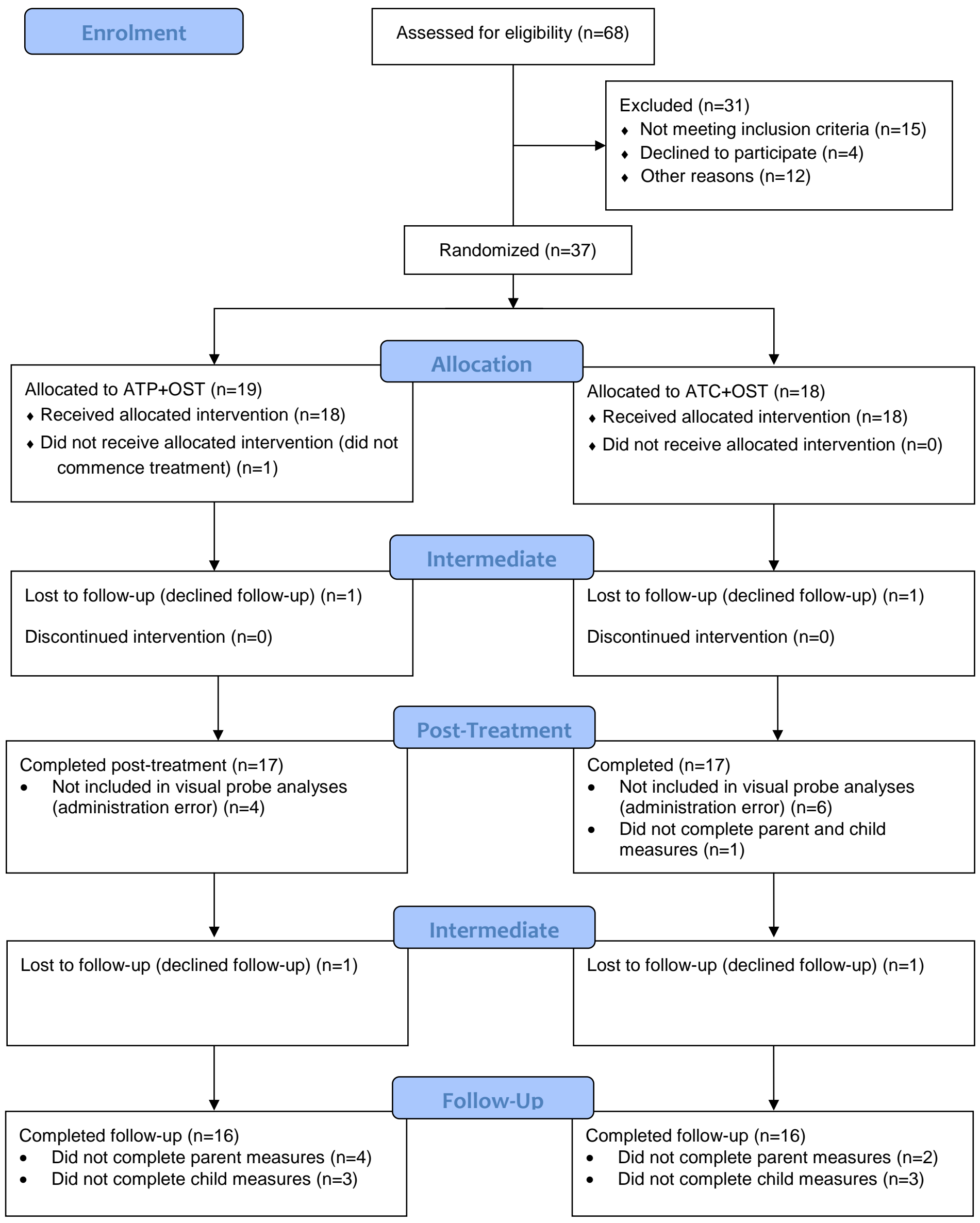

Figure 1: Flow of participants through the study. 
q

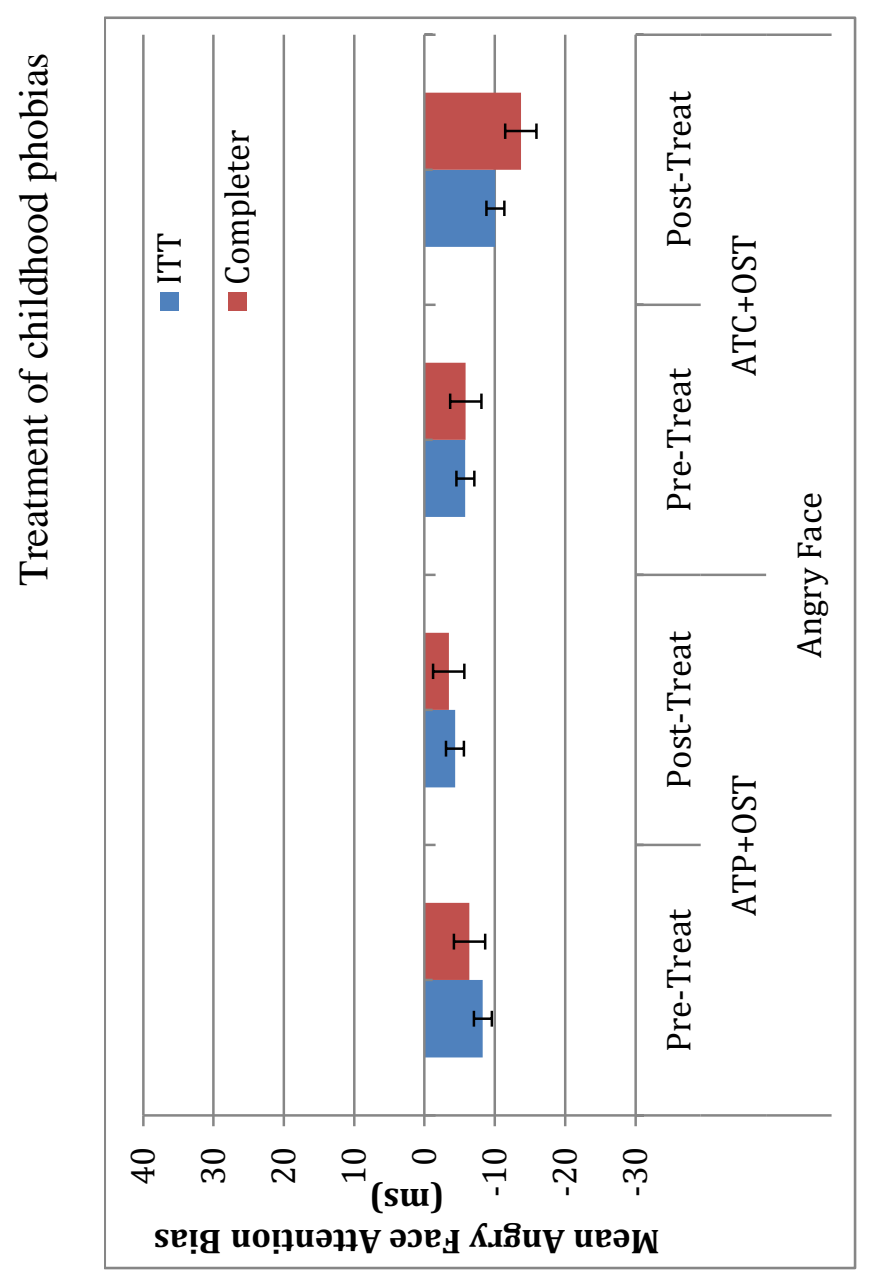

造

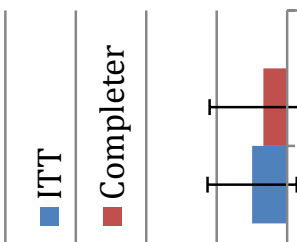

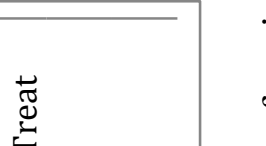

Õ. 

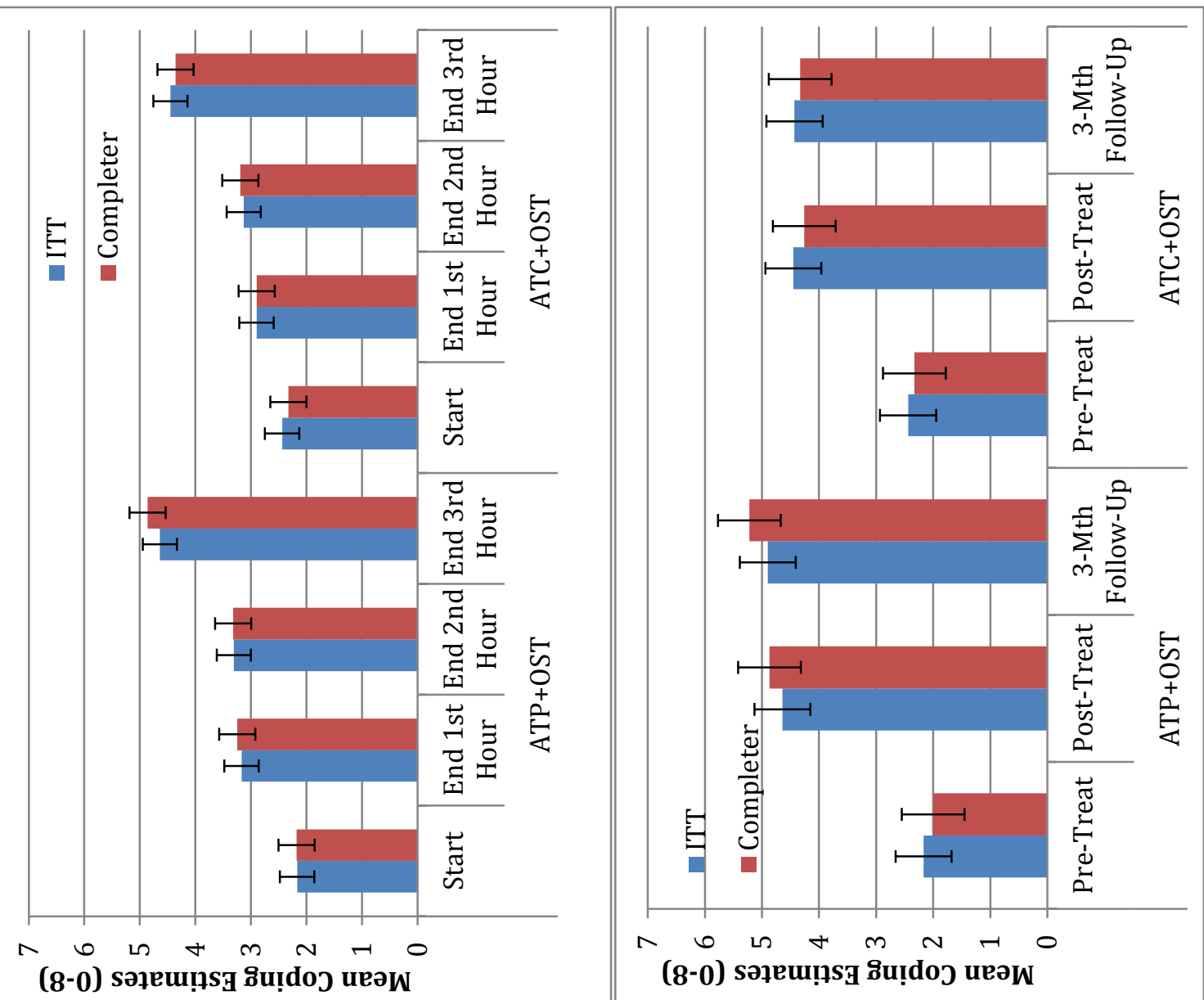

5
3
0
0
3
30
0
0
0
0
0
0
0
0
0
0
0
0
0
0
0
0
0
0
0
0
5
0
0
5
0
0
0

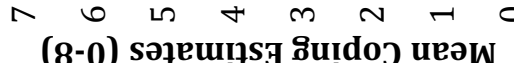

$\stackrel{\Xi}{\Xi}$

冓

罗

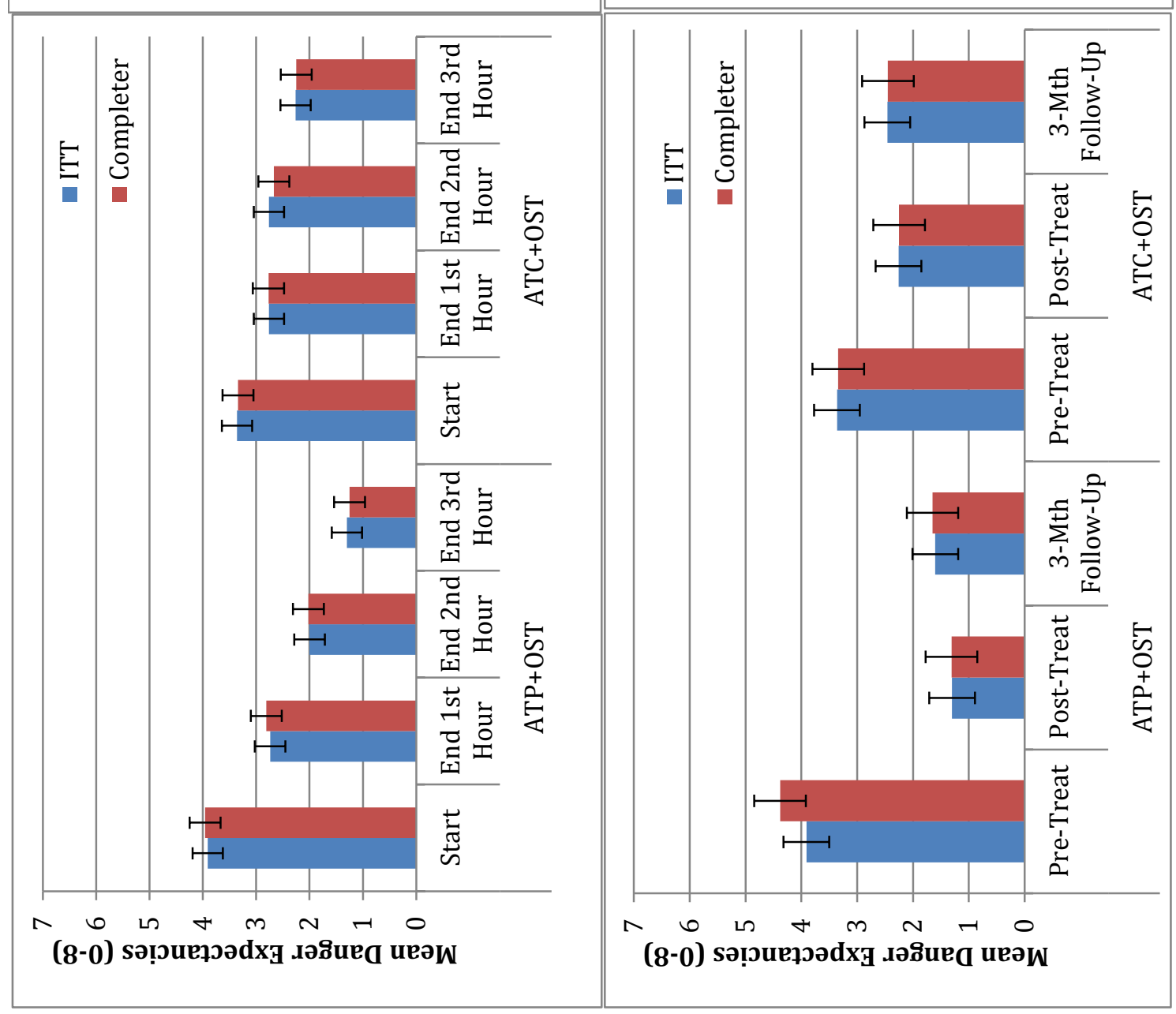

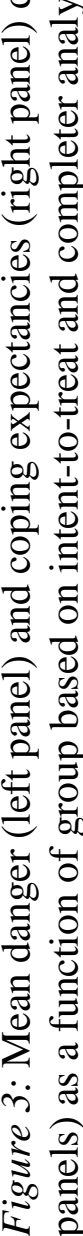




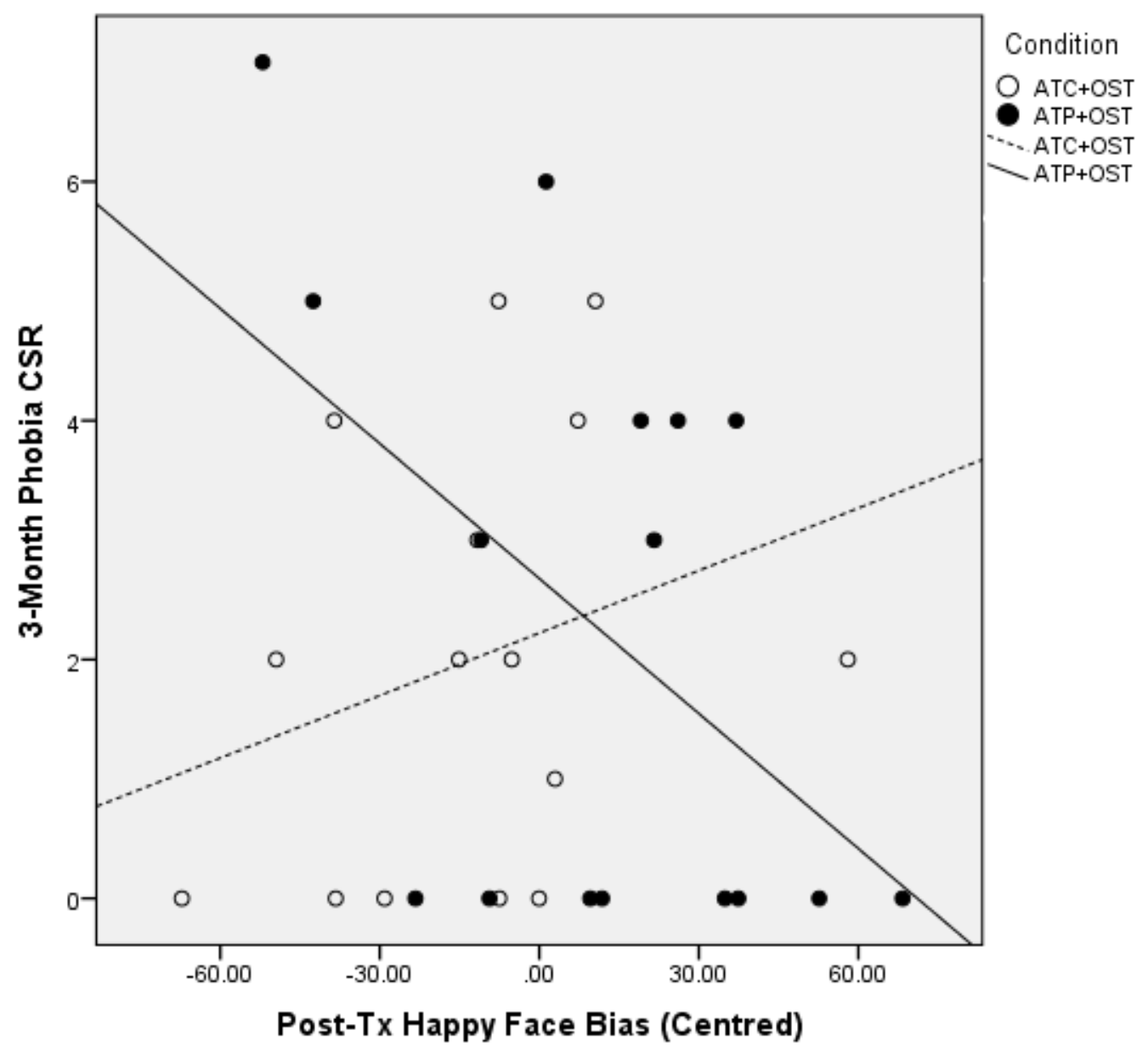

Figure 4: Associations between post-treatment attention bias towards happy faces and phobia diagnosis clinician severity rating at three-month post-treatment follow-up assessment as a function of group. 